\title{
The sodium bile salt cotransport family SLC10
}

\author{
Hagenbuch, Bruno ; Dawson, Paul
}

\begin{abstract}
The SLC10 family of sodium/bile salt cotransporters contains over 50 members in animal, plant and bacterial species. In man, two well-characterized members and three orphan transporters are known. The Na+/taurocholate cotransporting polypeptide (NTCP; SLC10A1) and the apical sodium-dependent bile salt transporter (ASBT; SLC10A2) are critical components of the enterohepatic circulation of bile salts. NTCP and ASBT are cotransporters that mediate sodium-dependent, electrogenic uptake of mainly bile salts into hepatocytes (NTCP), biliary epithelial cells, ileal enterocytes and renal proximal tubular cells (ASBT)
\end{abstract}

DOI: https://doi.org/10.1007/s00424-003-1130-z

Posted at the Zurich Open Repository and Archive, University of Zurich ZORA URL: https://doi.org/10.5167/uzh-155787

Journal Article

Published Version

Originally published at:

Hagenbuch, Bruno; Dawson, Paul (2004). The sodium bile salt cotransport family SLC10. Pflügers Archiv : European Journal of Physiology, 447(5):566-570.

DOI: https://doi.org/10.1007/s00424-003-1130-z 


\section{Bruno Hagenbuch • Paul Dawson \\ The sodium bile salt cotransport family SLC10}

Received: 5 February 2003 / Revised: 28 May 2003 / Accepted: 9 June 2003 / Published online: 8 July 2003

(C) Springer-Verlag 2003

\begin{abstract}
The SLC10 family of sodium/bile salt cotransporters contains over 50 members in animal, plant and bacterial species. In man, two well-characterized members and three orphan transporters are known. The $\mathrm{Na}^{+} /$taurocholate cotransporting polypeptide (NTCP; SLC1OA1) and the apical sodium-dependent bile salt transporter (ASBT; SLC10A2) are critical components of the enterohepatic circulation of bile salts. NTCP and ASBT are cotransporters that mediate sodium-dependent, electrogenic uptake of mainly bile salts into hepatocytes (NTCP), biliary epithelial cells, ileal enterocytes and renal proximal tubular cells (ASBT).
\end{abstract}

Keywords Bile salt - Enterohepatic circulation - NTCP . ASBT - Liver - Intestine - Proximal tubule - Cotransport

\section{Introduction}

Bile formation is essential for normal intestinal lipid digestion and absorption, cholesterol homeostasis, and for the hepatic excretion of lipid-soluble xenobiotics, drugs, and heavy metals. Bile secreted by the liver is composed mainly of bile salts ( 67\%), phospholipids, cholesterol and proteins. After their secretion, bile salts travel down the biliary tree and are stored in the gallbladder. In response to a meal the gallbladder empties its contents into the duodenum where the bile salts play an essential role in the efficient digestion and absorption of lipids and lipid soluble vitamins (i.e. vitamins A, D, E and K). In the

\footnotetext{
B. Hagenbuch (๘)

Division of Clinical Pharmacology and Toxicology, Department of Medicine,

University Hospital,

8091 Zurich, Switzerland

e-mail: Bruno.Hagenbuch@access.unizh.ch

Tel.: +41-1-6343151

Fax: +41-1-2554411

P. Dawson

Wake Forest University School of Medicine,

Winston-Salem, NC, USA
}

terminal ileum bile salts are absorbed almost quantitatively and return to the liver with the portal circulation. The small amount of fecal bile salt loss ( $\sim 5 \%$ of the total) is balanced by hepatic conversion of cholesterol to bile salts, a process representing an important route for elimination of cholesterol from the body. In the liver, bile salts are removed actively from portal blood and resecreted into bile (Fig. 1). Because this continuous flow of bile salts is restricted to the hepatocytes, the biliary tree, the intestine, and the portal blood, the system is called the enterohepatic circulation. This enterohepatic circulation is dependent on several transport systems, among which the two sodium-dependent bile salt cotransporters of the SLC10 family play a crucial role. The $\mathrm{Na}^{+} /$taurocholate cotransporting polypeptide (NTCP; SLC1OAI) located at the sinusoidal plasma membrane of hepatocytes (Fig. 1) extracts bile salts efficiently from portal blood for resecretion across the canalicular membrane into the bile. In parallel, the apical sodium-dependent bile salt transporter (ASBT; SLC10A2), expressed at the brush border membrane of ileocytes (Fig. 1), actively removes bile salts from the intestinal lumen and allows their return to the liver via the portal circulation. Most of the bile salts secreted by hepatocytes are not newly synthesized and have undergone enterohepatic recycling. As such, disturbances in bile salt synthesis, biliary secretion, and enterohepatic cycling all have profound effects on hepatic and gastrointestinal physiology.

\section{Brief history}

The rat Ntcp (SlclOal) was isolated by expression cloning using the Xenopus laevis oocyte system [1]. This cDNA was used subsequently to identify a human NTCP ortholog [2]. Two splice variants have been isolated subsequently from mouse liver [3]. Expression cloning was also employed to isolate the ASBT from a hamster ileal cDNA library [4]. This resulted in the subsequent identification of the rat [5], human [6], rabbit [7], and mouse [8] ASBT orthologs (Table 1). 
Fig. 1 Cellular localization of the SLC10 sodium bile salt cotransporters $\mathrm{Na}^{+} /$taurocholate cotransporting polypeptide $(N T C P)$ and the apical sodiumdependent bile salt transporter $(A S B T)$. While expression of NTCP is restricted to the sinusoidal membrane of hepatocytes, ASBT has been detected in the apical membranes of ileal enterocytes (ileocytes), of biliary endothelial cells (cholangiocytes) and of renal proximal tubular cells. Secretion of bile salts across the canalicular membrane of hepatocytes is accomplished by the ATP-dependent bile salt export pump (BSEP), while the proposed exchanger in the basolateral membrane of ileocytes has not yet been identified

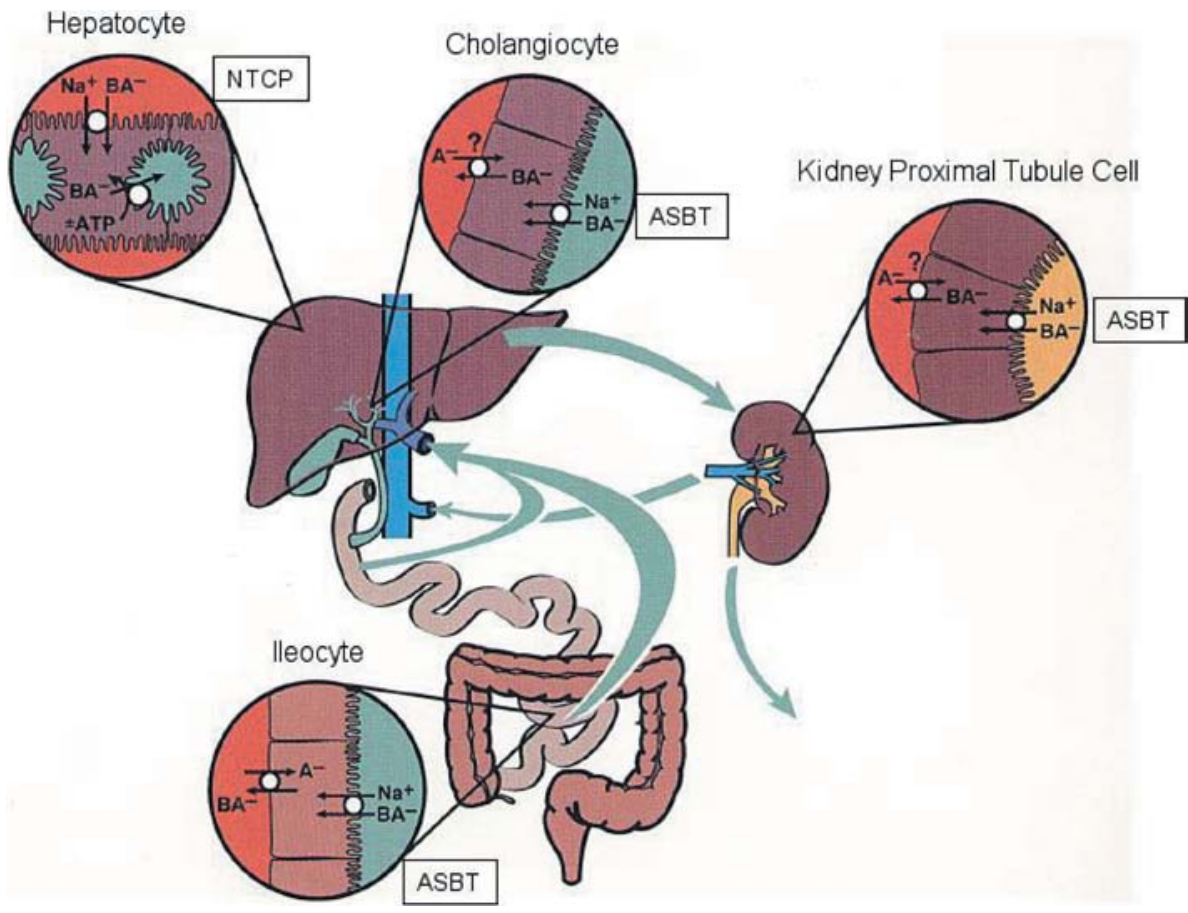

Table 1 SLC10 - the sodium bile salt cotransporter family

\begin{tabular}{|c|c|c|c|c|c|c|c|c|c|}
\hline $\begin{array}{l}\text { Human } \\
\text { gene } \\
\text { name }\end{array}$ & $\begin{array}{l}\text { Protein } \\
\text { name }\end{array}$ & Aliases & $\begin{array}{l}\text { Predomi- } \\
\text { nant } \\
\text { substrates }\end{array}$ & $\begin{array}{l}\text { Trans- } \\
\text { porter } \\
\text { type/ } \\
\text { coupling } \\
\text { ions* }\end{array}$ & $\begin{array}{l}\text { Tissue distribution } \\
\text { and cellular/ } \\
\text { subcellular } \\
\text { expression }\end{array}$ & $\begin{array}{l}\text { Link to } \\
\text { disease } \\
(\mathrm{OMIM})\end{array}$ & $\begin{array}{l}\text { Human } \\
\text { gene } \\
\text { locus }\end{array}$ & $\begin{array}{l}\text { Sequence } \\
\text { accession } \\
\text { ID }\end{array}$ & $\begin{array}{l}\text { Splice variants } \\
\text { and their } \\
\text { specific } \\
\text { features }\end{array}$ \\
\hline SLC10A1 & NTCP & LBAT & Bile salts & $\mathrm{C} / \mathrm{Na}^{+}$ & Liver, pancreas & & $14 q 24.1$ & NM_003049 & $\begin{array}{l}\text { Ntcp1/Ntcp2 } \\
\text { (mouse) }\end{array}$ \\
\hline SLC10A2 & ASBT & $\begin{array}{l}\text { IBAT, } \\
\text { ISBT }\end{array}$ & Bile salts & $\mathrm{C} / \mathrm{Na}^{+}$ & $\begin{array}{l}\text { Ileum, kidney, } \\
\text { biliary tract }\end{array}$ & $\begin{array}{l}\text { PBAM } \\
(601295)\end{array}$ & $13 \mathrm{q} 33$ & NM_000452 & tASBT (rat) \\
\hline SLC10A3 & P3 & & & $\mathrm{O}$ & $\begin{array}{l}\text { Ubiquitously (based } \\
\text { on EST data) }\end{array}$ & & $\mathrm{Xq} 28$ & NM_019848 & \\
\hline SLC10A4 & $\begin{array}{l}\text { Hypotheti- } \\
\text { cal protein } \\
\text { MGC29802 }\end{array}$ & & & $\mathrm{O}$ & $\begin{array}{l}\text { Brain neuroblastoma } \\
\text { (based on EST data) }\end{array}$ & & $4 \mathrm{p} 11$ & NM_152679 & \\
\hline SLC10A5 & $\begin{array}{l}\text { Similar to } \\
\text { P3 protein }\end{array}$ & & & $\mathrm{O}$ & $\begin{array}{l}\text { Fetal brain (based on } \\
\text { EST data) }\end{array}$ & & $8 \mathrm{q} 21$ & XM_294493 & \\
\hline
\end{tabular}

*C Cotransporter, $O$ orphan, EST expressed sequence tag

\section{Functional characteristics}

Both NTCP and the ASBT have been expressed in different recombinant systems including Xenopus laevis oocytes [1], COS-7 [9], CHO [10], HPCT-1E3 [11], MDCK [12, 13], HEK 293 [14], and rat hepatoma cells [15]. Both transport systems mediate $\mathrm{Na}^{+}$-dependent uptake of conjugated and unconjugated bile salts and the only non-bile salt substrate identified so far for NTCP is estrone-3-sulfate [10]. The driving force for NTCP- and ASBT-mediated bile salt uptake is provided by the inwardly directed $\mathrm{Na}^{+}$gradient maintained by the basolateral $\mathrm{Na}^{+}, \mathrm{K}^{+}$-ATPase as well as the negative intracellular potential. Detailed analysis has revealed that transport is electrogenic with a sodium:taurocholate stoichiometry of at least 2:1 [16,17]. Very recent studies of ASBT chimeras have shown that the benzothiazepinebased inhibitors interact with specific residues in the carboxyl-terminal transmembrane domain [18]. These data, as well as previous chemical modification experiments, indicate strongly that the two C-terminal putative transmembrane domains constitute an important part of the binding pocket for bile salts [14]. The importance of the C-terminal part of NTCP and ASBT is supported by the recent demonstration that the glutamic acid at position 257 as well as the cysteine at position 266 in rat Ntcp (both completely conserved among eight members of the 


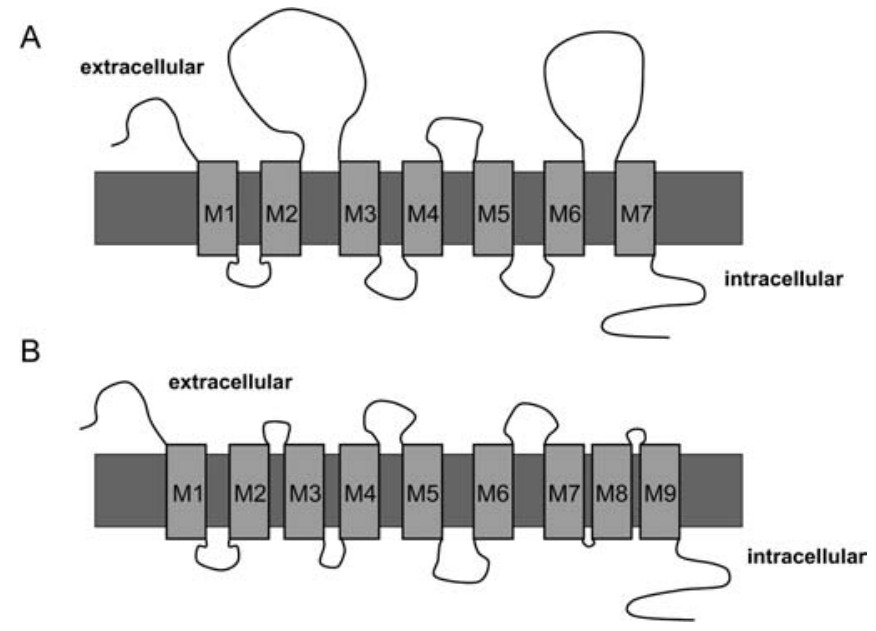

Fig. 2A, B Topological models of the SLC10 sodium bile salt cotransporters. Computer modeling suggests seven transmembrane $(M)$ domains (A) while experimental evidence is compatible with a nine-transmembrane domain model (B)

SLC10 transporters) are essential for taurocholate transport [19].

Computer programs have favored a seven-transmembrane domain topology for both NTCP and ASBT [2, 20]. However, recent experimental evidence based on translation/insertion scanning, alanine insertion and glycosylation site mutagenesis suggest rather a ninetransmembrane domain topology (Fig. 2) [21, 22]. Ultimately, an approach such as X-ray crystallography will be required to determine the topology.

\section{Individual members}

\section{SLC10A1}

The human NTCP is a 349-amino acid polytopic membrane glycoprotein with an apparent molecular mass of approximately $56 \mathrm{kDa}$ [2]. NTCP's expression at the basolateral (sinusoidal) membrane of human hepatocytes and high affinity for conjugated bile salts (taurocholate apparent $K_{\mathrm{m}} \sim 6 \mu \mathrm{M}$, taurochenodeoxycholate $\sim 2 \mu \mathrm{M}$ ) promotes efficient extraction of bile salts from portal blood to keep plasma concentrations at a minimum. In addition to the liver, Ntcp is also expressed at the luminal (apical) membrane of pancreatic acinar cells where it may function to clear any bile salts that leak into the terminal acini [23]. NTCP orthologs have been identified in the rat [1] (362 amino acids, 77\% amino acid identity to human NTCP), and mouse [3]. In contrast to humans and rat, the mouse Ntcp gene encodes two splice variants, Ntcp1 with 362 amino acids and the less-abundant Ntcp2 with 317 amino acids and a shorter C-terminal end [3].

NTCP's properties satisfy all the functional criteria for hepatocytic $\mathrm{Na}^{+}$-coupled bile salt uptake including: (a) preferential high affinity transport of conjugated bile salts, (b) kinetics for taurocholate transport similar to isolated hepatocytes, (c) electrogenic $\mathrm{Na}^{+}$-taurocholate uptake, (d) appropriate tissue-specific expression in the liver, and (e) similar ontogeny for $\mathrm{Na}^{+}$-dependent bile salt uptake and NTCP expression in development. The overwhelming evidence indicates that NTCP accounts for most, if not all, hepatic $\mathrm{Na}^{+}$-dependent bile salt transport $[24,25]$. NTCP mRNA and protein expression is decreased in various animal models of cholestasis and liver disease [26, 27]. In addition, recent studies have also shown similar decreased NTCP expression in percutaneous liver biopsies of patients with cholestatic liver disease [28]. An inherited defect in NTCP has not yet been reported. It is possible that an isolated NTCP gene defect is asymptomatic since the liver also expresses $\mathrm{Na}^{+}-$ independent bile salt transporters. However, a rare disorder characterized by a relatively isolated hypercholanemia has been described recently, and an NTCP defect remains a candidate for at least a subset of those patients [29].

\section{SLC10A2}

The human ASBT is a 348-amino acid polytopic membrane glycoprotein with an apparent molecular mass of approximately $50 \mathrm{kDa}$ [20]. ASBT transports all major species of bile salts, but favors trihydroxy (cholic acid, CA) over dihydroxy bile salts, and conjugated over unconjugated species. ASBT is expressed on the apical brush border membrane at high levels in terminal ileum and at lower levels in renal proximal tubules [30] and biliary epithelium [31]. In the ileum and kidney, ASBT functions as a salvage mechanism for efficient conservation of bile salts. In the bile ducts, ASBT's function may be to permit cholangiocytes to sample biliary contents to activate cellular signaling pathways rather than to transport significant quantities of bile salts [31]. ASBT shares approximately $35 \%$ amino acid identity with NTCP, and ASBT orthologs have been identified in the rat [5], mouse [7], hamster [4] and rabbit [7]. Alternative splicing gives rise to a novel truncated, 19-kDa form of ASBT in the rat. A significant proportion of the ASBT transcript undergoes exon-2 skipping, resulting in a frameshift at codon 126 and truncation of the ASBT protein from 348 to 154 amino acids. Preliminary evidence suggests that this truncated protein (tASBT) functions on the basolateral membrane as a bile salt efflux pump [32]. Notably, this is the first example of a solute carrier gene encoding both the solute uptake and efflux mechanisms.

The properties of ASBT satisfied all the functional criteria for ileal active bile salt uptake including: (a) a strict sodium dependence for bile salt transport, (b) narrow substrate specificity encompassing only conjugated and unconjugated bile salts with negligible uptake of other organic anions, (c) specific intestinal expression in the terminal ileum, and (d) similar ontogeny for ileal sodium-dependent taurocholate uptake and ASBT expression [33]. Finally, inherited mutations in the human ASBT gene cause primary bile salt malabsorption, an 
idiopathic intestinal disorder associated with interruption of the enterohepatic circulation of bile salts and fat malabsorption [34]. This last finding demonstrates clearly that most intestinal bile salt absorption in humans is mediated by ASBT.

\section{SLC10A3}

P3 cDNA was originally cloned from placenta and encodes a protein of 477 amino acids [35]. The function of the P3 protein is currently unknown. However, on the basis of its wide tissue expression and its conservation in distant animal species, $\mathrm{P} 3$ protein is thought to encode a protein with housekeeping functions. Since P3 shares approximately $27 \%$ amino acid identity with the ASBT and NTCP, it has been assigned to the "sodium/bile acid symporter" family. However, to date there is no experimental data indicating that the $\mathrm{P} 3$ protein functions in solute transport and its function remains a mystery.

\section{SLC10A4}

This hypothetical protein MGC29802 of 437 amino acids shares $\sim 37 \%$ identity with human NTCP. The function of MGC29802 is currently unknown. Based on expressed sequence tag (EST) database searches, MGC29802 appears to be expressed predominantly in neuroblastomas. However, its definitive tissue distribution as well as its function will have to be determined experimentally.

\section{SLC10A5}

This is the third predicted orphan transporter and consists of 297 amino acids and, based on EST data, is expressed in the fetal brain.

\section{SLC10 transporters as therapeutic targets}

Inhibitors for treatment of hypercholesterolemia and cholestasis

Inhibition of intestinal reabsorption of bile salts using binding resins was an important early therapeutic strategy for increasing hepatic cholesterol demand in order to elevate low-density lipoprotein (LDL) receptor levels and decrease plasma LDL. An alternative to luminal sequestration of bile salts by binding resins is to inhibit the intestinal absorption of bile salts directly. As a result of its intestinal expression and role in the enterohepatic circulation, ASBT is a potential target for cholesterol-lowering therapy and a variety of high-affinity inhibitors have been developed. These inhibitors fall into two general classes, bile salt-derivatives including bile salt dimers [36], and non-bile salt compounds including benzothiazepine [37] and benzothiepine analogs [38]. Two ileal bile salt transporter inhibitors have entered phase- 2 clinical trials with an associated reduction in LDL cholesterol of $10 \%$ reported in one trial [39].

\section{SLC10 transporters as portals for drug delivery}

With its restricted expression to hepatocytes NTCP is ideally suited to target drugs to the liver. Thus, any kind of liver-specific disease is a potential target for treatment with drugs that are conjugated to bile salts, but which, in an unconjugated form, do not home efficiently to the liver. Possible examples are e.g. anti-viral drugs or prodrugs to treat hepatitis, hydroxymethylglutaryl-coenzyme A (HMG-CoA) reductase inhibitors to lower cholesterol levels or cytostatic drugs to treat hepatocellular carcinomas. The feasibility of such an approach has been shown for several compounds such as e.g. antisense oligonucleotides, amino acids and peptides [40] as well as for cytostatic drugs which keep their potency even after conjugation to bile salts [41]. Similarly, oligopeptides coupled to bile salts are readily absorbed in the small intestine [42], which could be a useful way to improve the bioavailability of orally applied peptide drugs.

Acknowledgements The authors were supported by the Swiss National Science Foundation (grant 31-59204.99 to B.H.) and by the NIH (DK 47987 and HL49373 to P.A.D.).

\section{References}

1. Hagenbuch B, Stieger B, Foguet M, Lübbert H, Meier PJ (1991) Functional expression cloning and characterization of the hepatocyte $\mathrm{Na}^{+} /$bile acid cotransport system. Proc Natl Acad Sci USA 88:10629-10633

2. Hagenbuch B, Meier PJ (1994) Molecular cloning, chromosomal localization, and functional characterization of a human liver $\mathrm{Na}^{+}$bile acid cotransporter. J Clin Invest 93:1326-1331

3. Cattori V, Eckhardt U, Hagenbuch B (1999) Molecular cloning and functional characterization of two alternatively spliced Ntcp isoforms from mouse liver. Biochim Biophys Acta 1445:154-159

4. Wong MH, Oelkers P, Craddock AL, Dawson PA (1994) Expression Cloning and characterization of the hamster ileal sodium-dependent bile acid transporter. J Biol Chem 269:1340-1347

5. Shneider BL, Dawson PA, Christie DM, Hardikar W, Wong MH, Suchy FJ (1995) Cloning and molecular characterization of the ontogeny of a rat ileal sodium-dependent bile acid transporter. J Clin Invest 95:745-754

6. Oelkers P, Dawson PA (1995) Cloning and chromosomal localization of the human ileal lipid-binding protein. Biochim Biophys Acta 1257:199-202

7. Kramer W, Stengelin S, Baringhaus KH, Enhsen A, Heuer H, Becker W, Corsiero D, Girbig F, Noll R, Weyland C (1999) Substrate specificity of the ileal and the hepatic $\mathrm{Na}^{+} / \mathrm{bile}$ acid cotransporters of the rabbit. I. Transport studies with membrane vesicles and cell lines expressing the cloned transporters. J Lipid Res 40:1604-1617

8. Saeki T, Matoba K, Furukawa H, Kirifuji K, Kanamoto R, Iwami K (1999) Characterization, cDNA cloning, and functional expression of mouse ileal sodium-dependent bile acid transporter. J Biochem Tokyo 125:846-851 
9. Boyer JL, Ng OC, Ananthanarayanan M, Hofmann AF, Schteingart CD, Hagenbuch B, Stieger B, Meier PJ (1994) Expression and characterization of a functional rat liver $\mathrm{Na}^{+}$ bile acid cotransport system in COS-7 cells. Am J Physiol 266:G382-G387

10. Schroeder A, Eckhardt U, Stieger B, Tynes R, Schteingart CD, Hofmann AF, Meier PJ, Hagenbuch B (1998) Substrate specificity of the rat liver $\mathrm{Na}^{+} /$bile salt cotransporter in Xenopus laevis oocytes and in CHO cells. Am J Physiol 274:G370-G375

11. Platte HD, Honscha W, Schuh K, Petzinger E (1996) Functional characterization of the hepatic sodium-dependent taurocholate transporter stably transfected into an immortalized liver-derived cell line and V79 fibroblasts. Eur J Cell Biol 70:54-60

12. Walters HC, Craddock AL, Fusegawa H, Willingham MC, Dawson PA (2000) Expression, transport properties, and chromosomal location of organic anion transporter subtype 3. Am J Physiol 279:G1188-G1200

13. Sun AQ, Ananthanarayanan M, Soroka CJ, Thevananther S, Shneider BL, Suchy FJ (1998) Sorting of rat liver and ileal sodium-dependent bile acid transporters in polarized epithelial cells. Am J Physiol 275:G1045-G1055

14. Hallen S, Fryklund J, Sachs G (2000) Inhibition of the human sodium/bile acid cotransporters by side-specific methanethiosulfonate sulfhydryl reagents: substrate-controlled accessibility of site of inactivation. Biochemistry 39:6743-6750

15. Torchia EC, Shapiro RJ, Agellon LB (1996) Reconstitution of bile acid transport in the rat hepatoma McArdle RH-7777 cell line. Hepatology 24:206-211

16. Hagenbuch B, Meier PJ (1996) Sinusoidal (basolateral) bile salt uptake systems of hepatocytes. Semin Liver Dis 16:129-136

17. Weinman SA, Carruth MW, Dawson PA (1998) Bile acid uptake via the human apical sodium-bile acid cotransporter is electrogenic. J Biol Chem 273:34691-34695

18. Hallen S, Bjorquist A, Ostlund-Lindqvist AM, Sachs G (2002) Identification of a region of the ileal-type sodium/bile acid cotransporter interacting with a competitive bile acid transport inhibitor. Biochemistry 41:14916-14924

19. Zahner D, Eckhardt U, Petzinger E (2003) Transport of taurocholate by mutants of negatively charged amino acids, cysteines, and threonines of the rat liver sodium-dependent taurocholate cotransporting polypeptide Ntcp. Eur J Biochem 270:1117-1127

20. Wong MH, Oelkers P, Dawson PA (1995) Identification of a mutation in the ileal sodium-dependent bile acid transporter gene that abolishes transport activity. J Biol Chem 270:2722827234

21. Hallen S, Mareninova O, Branden M, Sachs G (2002) Organization of the membrane domain of the human liver sodium/bile acid cotransporter. Biochemistry 41:7253-7266

22. Hallen S, Branden M, Dawson PA, Sachs G (1999) Membrane insertion scanning of the human ileal sodium/bile acid cotransporter. Biochemistry 38:11379-11388

23. Kim JY, Kim KH, Lee JA, Namkung W, Sun AQ, Ananthanarayanan M, Suchy FJ, Shin DM, Muallem S, Lee MG (2002) Transporter-mediated bile acid uptake causes $\mathrm{Ca}^{2+}$-dependent cell death in rat pancreatic acinar cells. Gastroenterology 122:1941-1953

24. Kullak-Ublick GA, Stieger B, Hagenbuch B, Meier PJ (2000) Hepatic transport of bile salts. Semin Liver Dis 20:273-292

25. St-Pierre MV, Kullak-Ublick GA, Hagenbuch B, Meier PJ (2001) Transport of bile acids in hepatic and non-hepatic tissues. J Exp Biol 204:1673-1686

26. Trauner M, Meier PJ, Boyer JL (1998) Molecular pathogenesis of cholestasis. N Engl J Med 339:1217-1227

27. Lee J, Boyer JL (2000) Molecular alterations in hepatocyte transport mechanisms in acquired cholestatic liver disorders. Semin Liver Dis 20:373-384
28. Zollner G, Fickert P, Zenz R, Fuchsbichler A, Stumptner C, Kenner L, Ferenci P, Stauber RE, Krejs GJ, Denk H, Zatloukal K, Trauner M (2001) Hepatobiliary transporter expression in percutaneous liver biopsies of patients with cholestatic liver diseases. Hepatology 33:633-646

29. Lazaridis KN, Pham L, Tietz P, Marinelli RA, deGroen PC, Levine S, Dawson PA, LaRusso NF (1997) Rat cholangiocytes absorb bile acids at their apical domain via the ileal sodiumdependent bile acid transporter. J Clin Invest 100:2714-2721

30. Craddock AL, Love MW, Daniel RW, Kirby LC, Walters HC, Wong MH, Dawson PA (1998) Expression and transport properties of the human ileal and renal sodium-dependent bile acid transporter. Am J Physiol 274:G157-G169

31. Lazaridis KN, Pham L, Tietz P, Marinelli RA, deGroen PC, Levine S, Dawson PA, LaRusso NF (1997) Rat cholangiocytes absorb bile acids at their apical domain via the ileal sodiumdependent bile acid transporter. J Clin Invest 100:2714-2721

32. Lazaridis KN, Tietz P, Wu T, Kip S, Dawson PA, LaRusso NF (2000) Alternative splicing of the rat sodium/bile acid transporter changes its cellular localization and transport properties. Proc Natl Acad Sci USA 97:11092-11097

33. Shneider BL (2001) Intestinal bile acid transport: biology, physiology, and pathophysiology. J Pediatr Gastroenterol Nutr 32:407-417

34. Oelkers P, Kirby LC, Heubi JE, Dawson PA (1997) Primary bile acid malabsorption caused by mutations in the ileal sodium-dependent bile acid transporter gene (SLC10A2). J Clin Invest 99:1880-1887

35. Alcalay M, Toniolo D (1988) CpG islands of the X chromosome are gene associated. Nucleic Acids Res 16:9527-9543

36. Wess G, Kramer W, Enhsen A, Glombik H, Baringhaus KH, Boger G, Urmann M, Bock K, Kleine H, Neckermann G, Hoffmann A, Pittius C, Falk E, Fehlhaber HW, Kogler H, Friedrich M (1994) Specific inhibitors of ileal bile acid transport. J Med Chem 37:873-875

37. Root C, Smith CD, Sundseth SS, Pink HM, Wilson JG, Lewis MC (2002) Ileal bile acid transporter inhibition, CYP7A1 induction, and antilipemic action of 264W94. J Lipid Res 43:1320-1330

38. Tollefson MB, Vernier WF, Huang HC, Chen FP, Reinhard EJ, Beaudry J, Keller BT, Reitz DB (2000) A novel class of apical sodium co-dependent bile acid transporter inhibitors: the 2,3disubstituted-4-phenylquinolines. Bioorg Med Chem Lett $10: 277-279$

39. Stein EA, Rhyne JM, McKenney J, Bays H, Roth E, Breed S, Rolleri R (2001) Intestinal bile acid transport (IBAT) inhibition: results of a 4 week pilot study of $264 \mathrm{w} 94$, a novel IBAT inhibitor in hypercholesterolemia (abstract). XIV International Symposium on Drugs Affecting Lipid Metabolism. New York, Sept. 9-12, 2001

40. Petzinger E, Wickboldt A, Pagels P, Starke D, Kramer W (1999) Hepatobiliary transport of bile acid amino acid, bile acid peptide, and bile acid oligonucleotide conjugates in rats. Hepatology 30:1257-1268

41. Kullak-Ublick GA, Glasa J, Boker C, Oswald M, Grutzner U, Hagenbuch B, Stieger B, Meier PJ, Beuers U, Kramer W, Wess G, Paumgartner G (1997) Chlorambucil-taurocholate is transported by bile acid carriers expressed in human hepatocellular carcinomas. Gastroenterology 113:1295-1305

42. Kramer W, Wess G, Neckermann G, Schubert G, Fink J, Girbig F, Gutjahr U, Kowalewski S, Baringhaus KH, Boger G, Enhsen A, Falk E, Friedrich M, Glombik H, Hoffmann A, Pittius C, Urmann M (1994) Intestinal absorption of peptides by coupling to bile acids. J Biol Chem 269:10621-10627 